\title{
Mechanism whereby holotrich ciliates are retained in the reticulo-rumen of cattle
}

\author{
BY MATANOBU ABE AND TSUNENORI IRIKI \\ School of Veterinary Medicine, Azabu University, 1-17-71 Fuchinobe, Sagamihara-shi, \\ Kanagawa 229, Japan
}

(Received 7 February 1989 - Accepted 15 June 1989)

\begin{abstract}
The concentrations of holotrichs, reducing sugars and fermentation end-products, and the fluid dilution rates, in the cranial (CR), ventral (V) and caudal (CA) regions of the reticulo-rumen of cows were compared. Additionally, holotrich numbers in fluid and solid digesta samples taken from the dorsal (D) region were determined at different time-intervals. Holotrich numbers expressed per $\mathrm{ml}$ fluid at site $\mathrm{D}$ were almost twofold those expressed per $g$ solid digesta, and the fluctuation of their numbers in fluid preceded that in solid digesta. Holotrich concentrations at site $C R$ were higher before feeding than after feeding, while those at sites $\mathrm{V}$ and $\mathrm{CA}$ were lower before feeding than for a few hours after feeding. At sites $\mathrm{V}$ and $\mathrm{CA}$, holotrich concentrations fluctuated in good agreement with reducing sugar concentrations, but the increase in the former always preceded that in the latter. The concentration of volatile fatty acids (VFA) tended to decrease from site $C A$ to site $C R$, while the dilution rate was highest in site CR. The results suggest that migration of holotrichs from the reticulum to the rumen and vice versa are the cause of fluctuation in their numbers, and also the mechanism by which they are retained in the rumen of cattle.
\end{abstract}

Holotrich ciliates: Reticulo-rumen: Cow

Selective retention of ciliate protozoa within the rumen is essential for most of these organisms to survive in this organ (Abe \& Kumeno, 1973; Weller \& Pilgrim,1974; Hoover et al. 1976; Harrison et al. 1979; Leng, 1982). Holotrichs which have a longer generation time are more extensively retained in the rumen (Leng et al. 1981; Leng \& Nolan, 1984), and consequently only small proportions of those living in the rumen flow out to the lower digestive tract (Leng et al. 1986).

The concentration of holotrichs in the rumen of cattle exhibits a characteristic diurnal fluctuation. Concentrations are relatively low before feeding but begin to increase immediately after the commencement of feeding, and reach a maximum of two to ten times the prefeeding value in a few hours; they then decrease rapidly to the prefeeding level (Purser, 1961; Clarke, 1965; Abe et al. 1981, 1983; Murphy et al. 1985).

The aim of the present work was to identify the cause of the characteristic fluctuation of holotrich concentrations in the rumen of cattle and to examine the mechanism by which these ciliates are extensively retained.

A preliminary report of the present work has been published elsewhere (Abe et al. 1986).

\section{MATERIALS AND METHODS}

Expt 1

Two rumen-fistulated, non-lactating Holstein cows, weighing about 500 and $420 \mathrm{~kg}$, were used. In the first period of 3 weeks, one cow was given a low-roughage diet, while the other was given a high-roughage diet. The diets were reversed in the second 3-week period. The high-roughage diet consisted of five parts by weight Italian ryegrass (Lolium multiflorum) 
hay and one part by weight concentrate. The concentrate consisted of maize, sorghum grain, soya-bean meal, rapeseed (Brassica campestris) meal, lucerne (Medicago sativa) meal, bran and minerals, and contained $136 \mathrm{~g}$ crude protein (nitrogen $\times 6 \cdot 25$ ) and $680 \mathrm{~g}$ total digestible nutrients per $\mathrm{kg}$. The low-roughage diet consisted of one part by weight hay and five parts by weight concentrate. The daily ration was restricted to $0.013 \mathrm{~kg} / \mathrm{kg}$ bodyweight, and $40 \%$ of the daily amount was given at 09.00 hours and the remaining $60 \%$ at 17.00 hours. Water was freely available.

In the last week of each period, duplicate fluid samples were taken on $2 \mathrm{~d}$ from cranial $(\mathrm{CR})$, ventral (V) and caudal (CA) regions of the reticulo-rumen immediately before and 2 and $6 \mathrm{~h}$ after the commencement of morning feeding. The definition of the sites $\mathrm{CR}, \mathrm{V}$ and $\mathrm{CA}$ and the procedure for collection of fluid samples are described below.

\section{Expt 2}

Three rumen-fistulated, non-lactating Holstein cows, weighing about $650 \mathrm{~kg}$ (cow A and cow B) and $540 \mathrm{~kg}$ (cow C), were used. The diet consisted of timothy (Phleum pratense) hay and flaked maize $(7: 3, \mathrm{w} / \mathrm{w})$. The daily amount was restricted to $0.013 \mathrm{~kg} / \mathrm{kg}$ body-weight, and was given in two equal feeds at 09.00 and 17.00 hours. Water was freely available.

On the 17th day, 3 litres warm water containing $250 \mathrm{~g}$ polyethylene glycol (molecular weight 4000 ; PEG) were administered into the rumen through the fistula $1 \mathrm{~h}$ before the morning feed. Fluid samples were taken from three sites (CR, V and CA) within the reticulorumen at different time-intervals during the $8 \mathrm{~h}$ period after the commencement of morning feeding.

\section{Expt 3}

After the end of Expt 2, cows $\mathrm{B}$ and $\mathrm{C}$ continued to receive a ration similar to that given in Expt 2. On the 10th day (the 27th day from the beginning of Expt 2), fluid and solid digesta samples were simultaneously collected from the dorsal rumen (D) at different time-intervals.

\section{Collection of fluid and solid digesta samples}

Fluid samples were collected using a slightly bent plastic tube, $800-1000 \mathrm{~mm}$ long, i.d. 18 $\mathrm{mm}$, connected to an aspirator by a rubber tube and a sampling bottle. The end of the plastic tube was closed with a rubber stopper, but twelve small holes $5 \mathrm{~mm}$ in diameter were opened on the side surface of the tube within a range of $50 \mathrm{~mm}$ from the end. The fluid collected with this sampling device was devoid of large feed particles. In Expt 3, solid digesta samples were collected using large grasper-like tweezers.

When fluid samples were taken from site CR in Expts 1 and 2, the plastic tube was inserted into the rumen through the fistula, $80 \mathrm{~mm}$ i.d., sited in the hollow of the flank, towards the brisket as far as possible $(530-550 \mathrm{~mm}$ from the fistula in Expt 1, and 620-670 $\mathrm{mm}$ in Expt 2). When taken from site $\mathrm{V}$, the tube was inserted downward as far as possible (about $450 \mathrm{~mm}$ in Expt 1, and 510-540 mm in Expt 2). In the case of fluid collection from site CA, the tube was inserted towards the upper thigh as far as possible (about $400 \mathrm{~mm}$ in Expt 1, and 420-500 $\mathrm{mm}$ in Expt 2). The site D where fluid and solid digesta samples were collected in Expt 3 was about $150 \mathrm{~mm}$ beneath the fistula.

Although precise locations of the tube could not be defined, it was certain that the position of the end of the tube was almost the same on each occasion in each cow, and that sites $\mathrm{V}$ and $\mathrm{D}$ were situated within the ventral and dorsal sac of the rumen respectively. Sites $\mathrm{CR}$ and $\mathrm{CA}$ were assumed to be situated inside the reticulum and within the dorsal blind sac of the rumen respectively.

After their $\mathrm{pH}$ was measured, fluid samples were strained through two layers of gauze in order to facilitate further pipetting. The solid digesta collected was also strained through two layers of gauze, and the residues were washed twice with an isotonic solution containing $8 \mathrm{~g}$ sodium chloride/l. 


\section{Chemical analyses}

Protozoal counts and concentrations of ammonia- $N$ and volatile fatty acids (VFA) in rumen fluid were determined by the methods described previously (Abe \& Kumeno, 1973). The content of PEG was determined by the method of Buxton et al. (1979). Reducing sugars were quantified as glucose by the Somogyi-Nelson method described by Laboratories of Agricultural Chemistry, University of Tokyo (1973).

Samples for the determination of $\mathrm{NH}_{3}-\mathrm{N}, \mathrm{VFA}, \mathrm{PEG}$ and reducing sugars were stored at $-40^{\circ}$ until required for analysis.

\section{Estimation of dilution rate}

In order to examine whether fluid dilution rate differed between sites $C R, V$ and $C A$ within the reticulo-rumen, average dilution rates (Warner \& Stacy, 1968) over the $8 \mathrm{~h}$ period were estimated in Expt 2 by linear regression of time-interval(h) after the commencement of feeding $v$. natural logarithm of the concentration of PEG, on the assumption that the flow of PEG at each site follows a single-compartment model (Czerkawski, 1986).

\section{RESULTS}

Expt 1

There was a marked difference in the concentrations of entodiniomorphs, $\mathrm{NH}_{3}-\mathrm{N}$ and VFA between animals on the high-roughage and low-roughage diets, but less difference was observed in $\mathrm{pH}$ and the concentration of holotrichs (Fig. 1).

Patterns of fluctuation in concentrations of entodiniomorphs were similar between the sites irrespective of the diet. However, there was a marked difference between sites in the fluctuation of holotrich numbers. Occasionally, a remarkably high concentration of holotrichs was found immediately before the morning feed in samples taken from site CR, while at sites $\mathrm{V}$ and $\mathrm{CA}$ their concentrations were higher $2 \mathrm{~h}$ after the commencement of feedings.

When cows received the low-roughage diet, the concentrations of $\mathrm{NH}_{3}-\mathrm{N}$ and VFA tended to decrease from site CA to site CR, irrespective of the time-interval after feeding. In the case of cows receiving the high-roughage diet, however, a similar trend was seen only in the concentration of $\mathrm{NH}_{3}-\mathrm{N} 2 \mathrm{~h}$ after feeding and of VFA 2 and $6 \mathrm{~h}$ after feeding.

\section{Expt 2}

Fig. 2 shows the periodic changes in concentrations of holotrichs and reducing sugars at the different sites within the reticulo-rumen of cows given the high-roughage diet. In Expt 2 , cows $B$ and $C$ consumed half the daily ration within $0.5 \mathrm{~h}$, but cow $\mathrm{A}$ took $3 \mathrm{~h}$, consuming a portion of flaked maize within $0.5 \mathrm{~h}$ and the majority of hay between 2 and $3 \mathrm{~h}$ after the commencement of morning feeding.

The periodic change in holotrich concentrations at site CR was remarkably different from that at sites $\mathrm{V}$ and $\mathrm{CA}$ in all cows. At site $\mathrm{CR}$, holotrich concentrations were high until 15 min (cows A and B) or 30 min (cow C) after the commencement of morning feeding, and then decreased. Comparing cows, the tendency was most noticeable in cow $A$, and the prefeeding concentration of holotrichs at site CR was very high. At sites V and CA, however, their concentrations were lower than at site CR before feeding, but began to increase immediately after the commencement of feeding.

The reducing sugar concentrations increased in accordance with the ingestion of feed, but the increase was most marked at site $\mathrm{V}$. One of the most noteworthy observations was that the increase in holotrich concentrations at sites V and CA was always ahead of that in reducing sugar concentrations at both sites. 

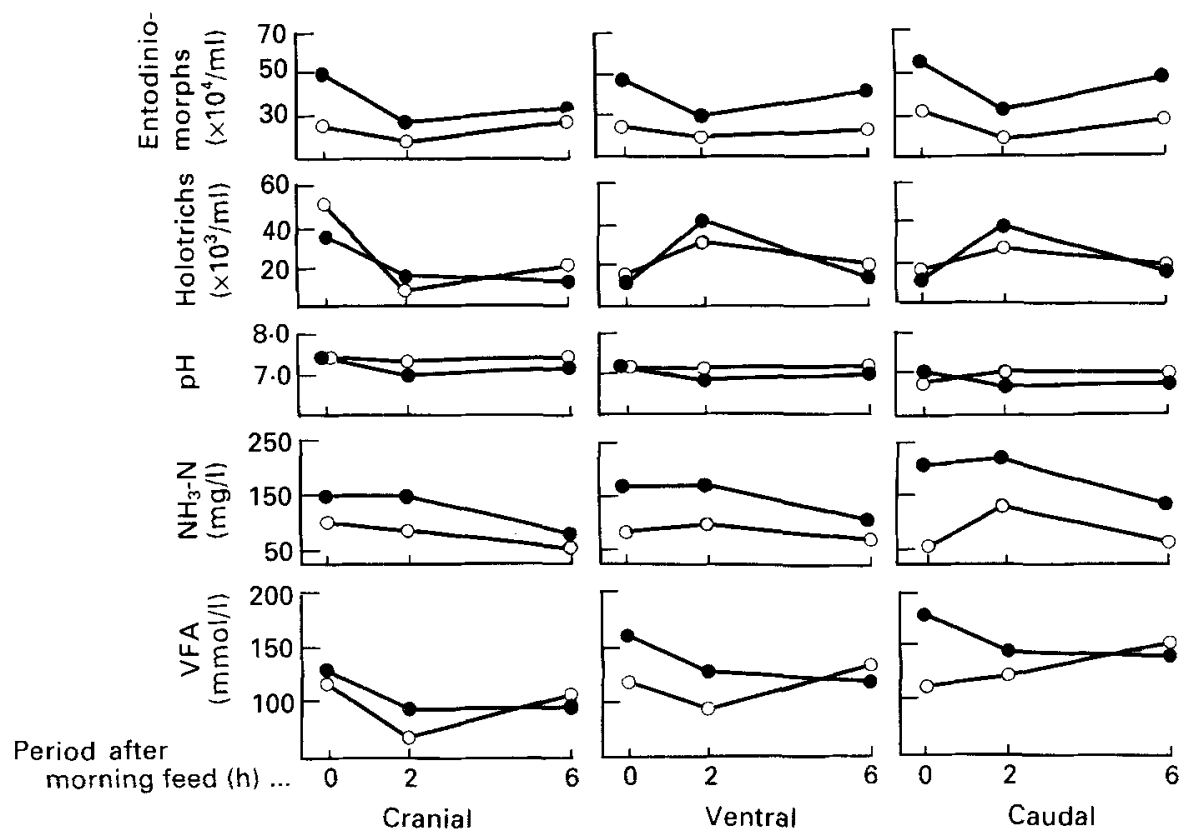

Site in reticulo-rumen

Fig. 1. Expt 1: Changes in $\mathrm{pH}$ and in the concentrations of entodiniomorphs, holotrichs, ammonia-nitrogen and volatile fatty acids (VFA) at cranial, ventral and caudal regions within the reticulo-rumen of cows receiving a highroughage diet $(O)$ or a low-roughage $\operatorname{diet}(\mathbf{C})$.
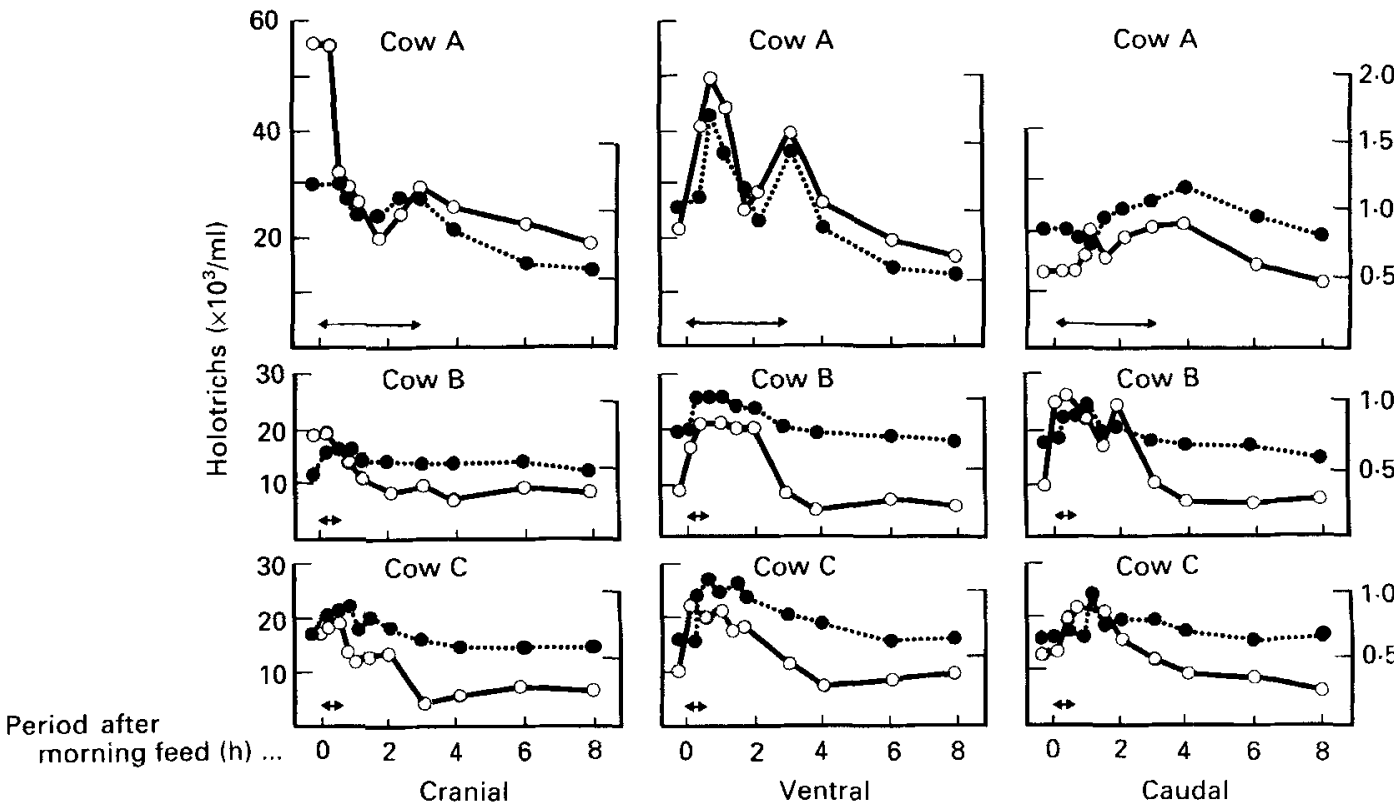

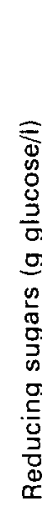
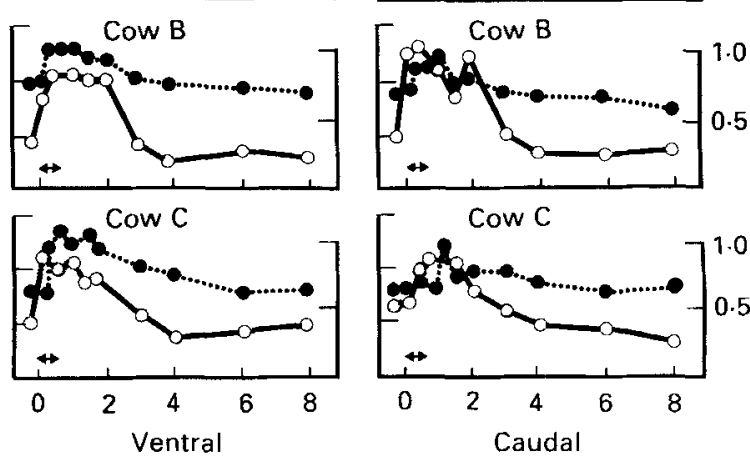

Site in reticulo-rumen

Fig. 2. Expt 2: Changes in the concentrations of holotrichs $(O)$ and reducing sugars $(O)$ at cranial, ventral and caudal regions within the reticulo-rumen of three cows fed on a high-roughage diet. $\leftrightarrow$, Duration of ingesting feed (for remarks on cow A, see p. 581). 


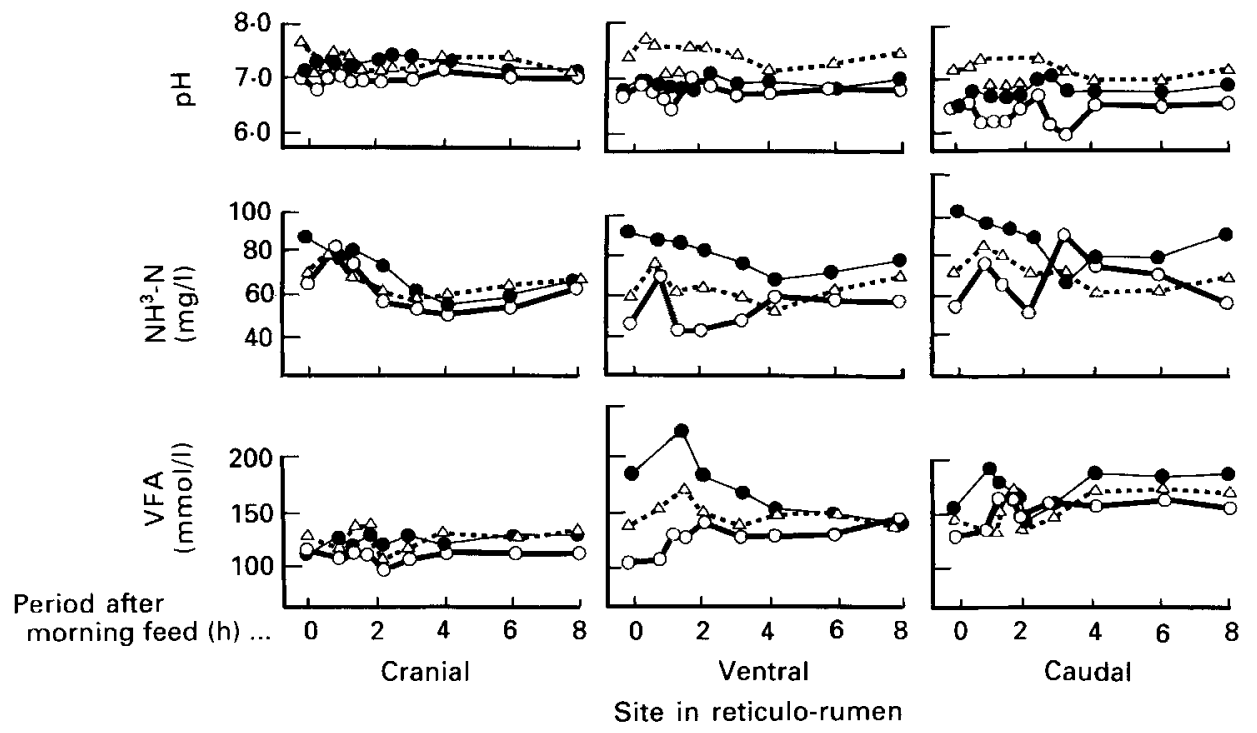

Fig. 3. Expt 2: Changes in $\mathrm{pH}$ and in the concentrations of ammonia-nitrogen and volatile fatty acids (VFA) at cranial, ventral and caudal regions within the reticulo-rumen of cows A $(O), B(O)$ and $C(\triangle)$ fed on a highroughage diet.

In Fig. 3, changes in $\mathrm{pH}$ and the concentrations of $\mathrm{NH}_{3}-\mathrm{N}$ and VFA were compared between sites within the reticulo-rumen of cows used in Expt 2.

At site CR, all values were more stable during the $8 \mathrm{~h}$ period, and variations within animals were much less, than at sites V and CA. Furthermore, the concentration of VFA tended to decrease from site CA to site CR in all cows, at least from a few hours after feeding. A similar trend was found in $\mathrm{NH}_{3}-\mathrm{N}$ concentration in cows $\mathrm{A}$ and $\mathrm{B}$, but not in cow $\mathrm{C}$, and no definite trend was observed in $\mathrm{pH}$.

Table 1 shows the average dilution rates over the $8 \mathrm{~h}$ period at sites CR, $\mathrm{V}$ and CA.

The dilution rate was found to be highest at site $\mathrm{CR}$ in all cows. The difference in the regression equation at site $\mathrm{CR}$ from that at the other sites and the high value of the correlation coefficient at site $C R$ in all cows both suggest that an independent pool in which inflow and outflow are almost balanced could be assumed at this site.

\section{Expt 3}

Fig. 4 shows the fluctuation in holotrich numbers in fluid and solid digesta samples taken from site $D$. The beginning of the increase in their numbers and attainment of the maximum value occurred $30 \mathrm{~min}$ later in the solid digesta than in the fluid. The numbers expressed per ml fluid were almost twice those expressed per g solid digesta, though the ratios of peak heights: prefeeding values were similar in both.

\section{DISCUSSION}

Cause of the characteristic fluctuation of holotrich concentrations in the rumen

The characteristic fluctuation in holotrich numbers in the rumen of cattle was first attributed to sequestration of organisms among either feed particles or papillae on the rumen wall (Purser, 1961), and later to a rapid multiplication and the successive bursting of cells due to overfilling with synthesized polysaccharide (Clarke 1965). However, little evidence had been obtained to support either hypothesis until an attachment of Isotricha to fresh 
Table 1. Expt 2. Linear regression between period ( $h$ ) after feeding (X) and natural logarithms of the concentration of polyethylene glycol in fluid $(\mathrm{Y})$, and average dilution rates over the $8 \mathrm{~h}$ period at cranial $(C R)$, ventral $(V)$ and caudal $(C A)$ regions within the reticulorumen of three cows*

\begin{tabular}{|c|c|c|c|c|}
\hline \multirow[b]{2}{*}{ Cow } & \multirow[b]{2}{*}{ Site } & \multicolumn{2}{|c|}{ Regression } & \multirow{2}{*}{$\begin{array}{c}\text { Dilution rate } \\
(/ \mathrm{h})\end{array}$} \\
\hline & & Equation & Coefficient & \\
\hline $\mathrm{A}$ & $\begin{array}{l}\mathrm{CR} \\
\mathrm{V} \\
\mathrm{CA}\end{array}$ & $\begin{array}{l}Y=-0.083 X+5.999 \\
Y=-0.050 X+5.956 \\
Y=-0.044 X+5.974\end{array}$ & $\begin{array}{l}-0.952 \\
-0.920 \\
-0.568\end{array}$ & $\begin{array}{l}0 \cdot 083 \\
0 \cdot 050 \\
0 \cdot 044\end{array}$ \\
\hline B & $\begin{array}{l}\mathrm{CR} \\
\mathrm{V} \\
\mathrm{CA}\end{array}$ & $\begin{array}{l}Y=-0.098 X+4.927 \\
Y=-0.065 X+5.264 \\
Y=-0.081 X+5.554\end{array}$ & $\begin{array}{l}-0.924 \\
-0.918 \\
-0.891\end{array}$ & $\begin{array}{l}0 \cdot 098 \\
0 \cdot 065 \\
0 \cdot 081\end{array}$ \\
\hline C & $\begin{array}{l}\mathrm{CR} \\
\mathrm{V} \\
\mathrm{CA}\end{array}$ & $\begin{array}{l}Y=-0 \cdot 107 X+5 \cdot 539 \\
Y=-0.080 X+5 \cdot 718 \\
Y=-0.086 X+5.564\end{array}$ & $\begin{array}{l}-0.919 \\
-0.927 \\
-0.923\end{array}$ & $\begin{array}{l}0 \cdot 107 \\
0.080 \\
0.086\end{array}$ \\
\hline
\end{tabular}

* For details of calculations, see p. 581 .

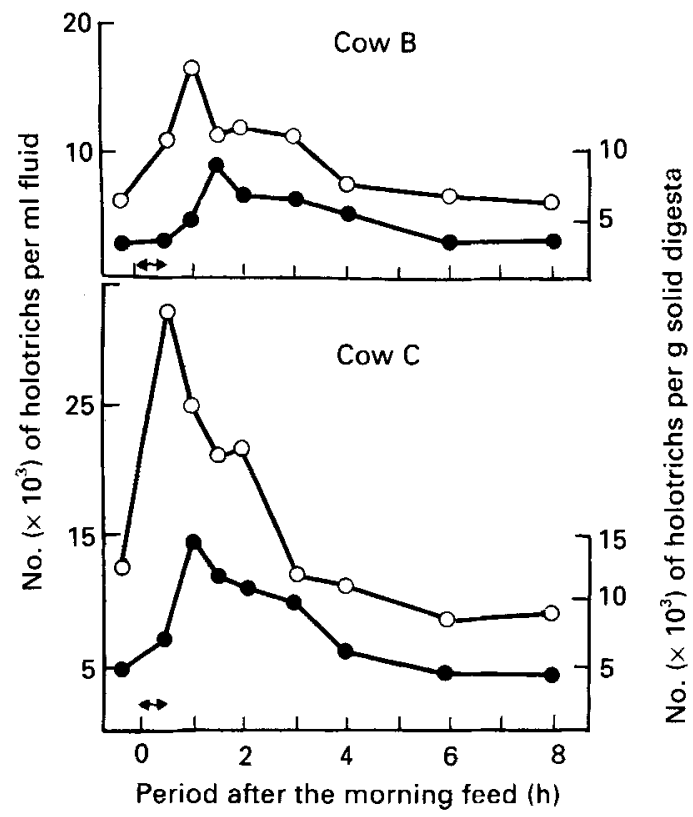

Fig. 4. Expt 3: Changes in holotrich numbers in fluid $(O)$ and solid digesta $(O)$ taken from the dorsal rumen of two cows. $\leftrightarrow$, Duration of ingesting feed.

plant particles during the first $2 \mathrm{~h}$ after feeding was reported (Orpin \& Hall, 1977; Orpin \& Letcher, 1978).

Attachment or sequestration of holotrichs in solid digesta during the first few hours after feeding was also supported by the present work (Fig. 4). However, such sequestration or attachment does not seem to provide an adequate explanation of the increase in holotrich numbers in fluid during the first few hours after feeding, although it may be one cause of the subsequent decrease. 
Previously we observed a thick holotrich mass inside the honeycomb structure on the reticulum wall (Abe et al. 1981). We have not subsequently found such a thick mass, but recently Abe \& Iriki (1989) found that the holotrichs attached to the reticulum wall were similar in number to those existing in whole rumen contents, more than twofold those on the rumen wall, and about sevenfold those in the reticulum contents in a cow killed after fasting for $20 \mathrm{~h}$, even though the holotrich mass on the reticulum wall was invisible to the naked eye. In contrast, entodiniomorphs in whole rumen contents were 140 -fold those on the reticulum wall, and seventyfold those in the reticulum contents.

These observations suggest that the rapid increase in holotrich concentrations in the rumen immediately after feeding could be due to the prefeeding sequestration of organisms within the reticulum and to successive migration into the rumen after feeding. This hypothesis was partly demonstrated by Murphy et al. (1985) who observed a fivefold increase in holotrich concentration in the rumen after the injection of glucose into the reticulum of Holstein steers.

Recently, Dehority \& Tirabasso (1989) proposed that sequestration of holotrichs may occur in sheep as a result of settlement in the ventral rumen. However, the results of the present work indicate that sequestration occurs in the cranial rather than the ventral region of the reticulo-rumen, at least in cattle.

Although a very high density of holotrichs was occasionally found at site CR before feeding (Figs. 1 and 2), this does not necessarily indicate that sequestration occurs at this site, because their concentration at site CR showed little increase even when those at sites $\mathrm{V}$ and CA began to decrease from a few hours after feeding (Fig. 2). In addition, if holotrichs stay in high density at this site for a long period, they would easily be washed out with fluid at a higher dilution rate (Table 1).

Because of the structure of the sampling device used, the site CR is not assumed to be on the reticulum wall. It seems most probable that holotrichs would sequester inside the honeycomb structure on the reticulum wall, as shown previously (Abe et al. 1981).

\section{Factors concerning the migration from the reticulum into the rumen}

One of the factors causing migration from the reticulum into the rumen would be chemical stimuli from soluble sugars (Murphy et al. 1985). The findings of the present work, however, suggest that factor(s) other than the chemotactic response to soluble sugars are also involved in the migration, because (1) a very high density of holotrichs was occasionally found at site CR before the ingestion of feed (Figs 1 and 2), and (2) the initiation of the increase in holotrich concentrations at sites $\mathrm{V}$ and $\mathrm{CA}$ always preceded that of the increase in reducing sugar concentrations (Fig. 2).

A prefeeding increase in holotrich concentrations in the rumen was reported by Dehority \& Mattos (1978) as an exceptional case in cattle, but has been generally observed in sheep (Warner, 1962, 1966; Abe et al. 1983), in goats (Abe et al. 1983) and in water buffalo (Bubalus bubalus) (Michalowski, 1975, 1977). Recently, Dehority \& Tirabasso (1989) suggested that the amount of polysaccharide stored in the holotrich cells may be another factor controlling migration into the rumen. They termed this a depletion response rather than a chemotactic response, and attributed the prefeeding increase observed in the rumen of sheep to the depletion response. In the present work, the high density of holotrichs detected at site CR before the morning feed ( $16 \mathrm{~h}$ after the previous feed) may be attributed to the depletion response, because no increase was observed in their concentration before the evening feed ( $8 \mathrm{~h}$ after the morning feed). The effect on holotrich numbers in the rumen seems much less in cattle than in sheep. In our previous work using sheep and goats given diets twice daily at fixed hours (Abe et al. 1983), delayed feeding caused an obvious increase in rumen holotrich numbers near the ordinary feeding time, without actual ingestion of 
feed, a response that resembled a conditioned reflex. These observations, as well as the present results described above as item (2), seem to indicate that some kind of contractile movement of the reticulum at feeding may also be involved in the migration of holotrichs into the rumen.

\section{Factors concerning the migration from the rumen to the reticulum}

The results in Fig. 2 suggest that the exhaustion of soluble sugars could be a factor involved in the return of holotrichs from the rumen to the reticulum, but it could only be a stimulus for their return.

If large numbers of holotrichs are attached to solid digesta after feeding, chewing the cud during rumination may result in the release and accumulation of organisms in the reticulum. From the present work, however, this possibility seems to be minor or nonexistent, as indicated by Fig. 4.

The concentration of VFA within the reticulo-rumen tended to decrease from site CA to site CR irrespective of the diet at least from a few hours after feeding (Figs 1 and 3), suggesting that the concentration gradient of VFA could be a factor in the return to the reticulum. Holotrichs may begin to migrate towards the reticulum as a negative chemotactic response to VFA when soluble sugar concentrations become low within the rumen. It is considered that the lowest concentration of VFA at site CR could be a result, at least partially, of the dilution rate of fluid at this site (the highest of the three sites examined), nearest to the reticulo-omasal orifice (Table 1).

It is unclear whether special factors are needed for holotrichs to form a mass inside the honeycomb structure (Abe et al. 1981) after they return to the reticulum.

\section{REFERENCES}

Abe, M. \& Iriki, T. (1989). Characteristic diurnal variation of holotrich concentrations in the rumen of cattle: a sequestration-migration theory. Proceedings of the Japanese Society for Animal Nutrition and Metabolism 33, $77-96$.

Abe, M., Iriki, T., Tobe, N. \& Shibui, H. (1981). Sequestration of holotrich protozoa in the reticulo-rumen of cattle. Applied and Environmental Microbiology 41, 758-765.

Abe, M. \& Kumeno, F. (1983). In vitro simulation of rumen fermentation: apparatus and effects of dilution rate and continuous dialysis on fermentation and protozoal population. Journal of Animal Science 36, 941-948.

Abe, M., Suzuki, Y., Okano, H. \& Iriki, T. (1983). Specific difference in fluctuation pattern of holotrich concentration in the rumen of cattle, goat and sheep. Japanese Journal of Zootechnical Science 54, 457-462.

Abe, M., Nakagawa, Y. \& Iriki, T. (1986). Comparison of the nature among different sites in the rumen of cows fed rations differing in hay: concentrate ratio. Japanese Journal of Zootechnical Science 57, 395-403.

Buxton, T. B., Crockett, J. K., Moore, W. L. III, Moore, W. L. Jr \& Pissing, J. P. (1979). Protein precipitation by acetone for the analysis of polyethylene glycol in intestinal perfusion fluid. Gastroenterology 76, 820-824.

Clarke, R. T. J. (1965). Diurnal variation in the numbers of rumen ciliate protozoa in cattle, New Zealand Journal of Agricultural Research 8, $1-9$.

Czerkawski, J. W. (1986). An Introduction to Rumen Studies, pp. 31-49. Oxford: Pergamon Press.

Dehority, B. A. \& Mattos, W. R. S. (1978). Diurnal changes and effect of ration on concentration of rumen ciliate Charon ventriculi. Applied and Environmental Microbiology 36, 953-958.

Dehority, B. A. \& Tirabasso, P. A. (1989). Factors affecting the migration and sequestration of rumen protozoa in the family Isotrichidae. Journal of General Microbiology 135, 539-548.

Harrison, D. G., Beever, D. E. \& Osbourn, D. F. (1979). The contribution of protozoa to the protein entering the duodenum of sheep. British Journal of Nutrition 41, 521-527.

Hoover, W. H., Crooker, B. A. \& Sniffen, C. J. (1976). Effects of differential solid-liquid removal rates on protozoa numbers in continuous cultures of rumen contents. Journal of Animal Science 43, 528-534.

Laboratories of Agricultural Chemistry, University of Tokyo (editors) (1973). Experimental Agricultural Chemistry, pp. 324-326. Tokyo: Asakura Book Co., Ltd.

Leng, R. A. (1982). Dynamics of protozoa in the rumen of sheep. British Journal of Nutrition $48,399-415$.

Leng, R. A., Dellow, D. \& Waghorn, G. (1986). Dynamics of large ciliate protozoa in the rumen of cattle fed on diets of freshly cut grass. British Journal of Nutrition 56, 455-462.

Leng, R. A., Gill, M., Kempton, T. J., Rowe, J. B., Nolan, J. V., Stachiew, S. J. \& Preston, T. P. (1981). Kinetics of large ciliate protozoa in the rumen of cattle given sugar cane diets. British Journal of Nutition 46, 371-384. 
Leng, R. A. \& Nolan, J. V. (1984). Nitrogen metabolism in the rumen. Journal of Dairy Science 67, 1072-1089. Michalowski, T. (1975). Effect of different diets on the diurnal concentrations of ciliate protozoa in the rumen of water buffalo. Journal of Agricultural Science 85, 145-150.

Michalowski, T. (1977). Diurnal changes in concentration of rumen ciliates and in occurrence of dividing forms in water buffalo (Bubalus bubalus) fed once daily. Applied and Environmental Microbiology 33, 802-804.

Murphy, M. R., Drone, P. F. Jr \& Woodford, S. T. (1985). Factors stimulating migration of holotrich protozoa into the rumen. Applied and Environmental Microbiology 49, 1329-1331.

Orpin, C. G. \& Hall, F. J. (1977). Attachment of the rumen holotrich protozoon Isotricha intestinalis to grass particles. Proceedings of the Society for General Microbiology 4, 82-83.

Orpin, C. G. \& Letcher, A. J. (1978). Some factors controlling the attachment of the rumen holotrich protozoa Isotricha intestinalis and $I$. prostoma to plant particles in vitro. Journal of General Microbiology 106, 33-40.

Purser, D. B. (1961). A diurnal cycle for holotrich protozoa in the rumen. Nature 190, 831-832.

Steinhour, W. D., Stokes, M. R., Clark, J. H., Rogers, J. A. \& Davis, C. L. (1982). Estimation of the proportion of non-ammonia-nitrogen reaching the lower gut of the ruminant derived from bacteria and protozoa nitrogen. British Journal of Nutrition 48, 417-431.

Warner, A. C. I. (1962). Some factors influencing the rumen microbial population. Journal of General Microbiology 28, 129-146.

Warner, A. C. I. (1966). Diurnal changes in the concentration of micro-organisms in the rumens of sheep fed limited diets once daily. Journal of General Microbiology 45, 213-235.

Warner, A. C. I. \& Stacy, B. D. (1968). The fate of water in the rumen. 1. A critical appraisal of the use of soluble markers. British Journal of Nutrition 22, 369-387.

Weller, R. A. \& Pilgrim, A. F. (1974). Passage of protozoa and volatile fatty acids from the rumen of sheep and from a continuous in vitro fermentation system. British Journal of Nutrition 32, 341-351. 